\title{
Photo-Assisted Organic Pollutants Sensing by a Wide Gap pn Heterojunction
}

\author{
Yoshinobu Nakamura ${ }^{1}$, Yusuke Morita ${ }^{2}$, Yui Ishikura², \\ Hidenori Takagi ${ }^{1}$ and Satoru Fujitsu ${ }^{3}$ \\ ${ }^{1}$ The University of Tokyo, \\ ${ }^{2}$ Shonai Institute of Technology, \\ ${ }^{3}$ Tokyo Institute of Technology, \\ clopan
}

\section{Introduction}

Since the industrial revolution, living environment is little by little changed to the worse due to the air and soil pollution. The etiological compounds are chemical bi-product from industries, whose accumulation in atmosphere have been negative legacy of overreached materials civilization for a long time. The advanced emission control technology in the advanced nations gradually decreases the total amount of harmful chemical substances spread to atmosphere, however, more than two hundred of harmful compounds have still been contaminating our living environment. Among these compounds, the emission of toluene, benzene, xylene and formaldehyde are in higher level. We have a risk of the health hazard by continuous breathing in these compounds.

Recently, not only outdoors, but also indoor air pollutions by these compounds are regarded as social problems. Man suffers from the strange disease named "sick building syndrome", associated with continuous breathing in benzene, toluene, formaldehyde, or other harmful volatile organic compounds (VOCs), which are evaporated from adhesive, paint, or synthetic building materials, etc. From the viewpoint of maintenance of safe environment, there is currently great interest in the development of VOC sensors for the applications involving environmental monitoring. Up to now, gas chromatography (GC) or gas chromatography mass-spectroscopy (GC-MS) systems have been applied for this purpose, however, such an analytical method had disadvantage of higher running cost and complicated operation including gas sampling by engineers or surveyors. In addition, their slow response is not appropriate for real-time environmental monitoring.

For the simplest and low-cost solid-state device for VOC detection, a semiconductor gas sensor and its peripheral technology have been paid much attention. The working mechanisms of a semiconductor gas sensor are described later, but simply speaking, the modulation in electric resistance accompanied by the catalytic oxidation reaction of testing gases over a sensor body. For the operation of a traditional semiconductor gas sensor, the activation energy for the chemical reaction is provided by the lattice vibration activated under the elevated temperature ranging $150-600{ }^{\circ} \mathrm{C}$. As a heat source for the gas sensor 
operation, on-chip micro-heaters are often adopted, however, additional heating system causes the complexity in the sensor system and it should be omitted if possible. If a semiconductor gas sensor has sufficient sensitivity for VOCs at room temperature, both sensing element and its operation system can be embedded in one IC tip. Such a system will become a powerful tool for in situ environmental monitoring. The most desirable sensor system for environmental monitoring is a VOC sensor especially for toluene and benzene. Thermodynamically stable aromatic VOCs hardly interact with the surface of the solid-state sensor devices at moderate temperature region and even if an oxide semiconductor could work as an aromatic VOC sensor, severe operating conditions, higher operation temperature (typically $>450^{\circ} \mathrm{C}$ ), will usually be required.

How to activate the thermodynamically stable molecules is a key for designing a solid-state VOC sensor with lower operation temperature. For this purpose, the authors will propose new concepts for gas sensing under a mild condition, whose working mechanism is based on the assistance of "external" energy, electric potential energy and photon energy. A semiconductor pn junction devise is applied for the reaction field of a gas sensor system, because the active carrier (hole in VB: Valence Band) can efficiently injected into VOC molecule over the junction interface. Detail in our strategy is shown in the next chapter. Both electron and photon can supply the several eV order of energy, corresponding to the thermal energy of over $10000 \mathrm{~K}$. A pn junction devise is appropriate for the use of such colossal energy supplied by photons or electron holes. Our results will provide a "chemical" application of wide gap oxide semiconductor heterojunction devises, which had been paid much attention for their application to UV-LDE or UV detectors.

\section{VOC sensing using an oxide semiconductor -How to oxidize of thermodynamic stable molecules}

The working principle of a semiconductor gas sensor is based in the catalytic oxidation of testing gas molecules over a sensor body. A simple model for the gas sensor operation of $\mathrm{n}$ type semiconductor, for example, $\mathrm{SnO}_{2}, \mathrm{ZnO}$, etc. is summarized in Figure 1. In air, the surface of an oxide semiconductor tends to be charged negatively due to the surface excess anions, i.e., adsorbed oxygen ions coordinated to surface cations (Figure 1(A)). For the compensation of this excess negative charge $\left(\delta^{-}\right.$in Figure 1(B)) originated from adsorbates, the space charge layer with opposite charge $\left(\delta^{+}\right)$is induced near surface, then, in the case of a $n$-type semiconductor, the surface conductivity becomes smaller than that of the semiconductor bulk. Guessing from this situation, the conductance of a sensor element changes as a function of the total amount of the effective charge by the adsorbates, which would be changed by the catalytic reaction with gas molecules in atmosphere.

When combustible gas molecules are introduced in atmosphere, the surface band bending of an oxide semiconductor will become gentle depending on the nature of the surface adsorbed species as is illustrated in the lower part of Figure 1(B). For example, $\left(\mathrm{C}_{m} \mathrm{H}_{n}\right)$ with an oxide semiconductor surface and sometimes molecularly adsorbed species $\left(\mathrm{C}_{m} \mathrm{H}_{n}\right.$ ads $)$ donates electrons to the semiconductor bulk. This process is regarded as partial oxidation of $\mathrm{C}_{m} \mathrm{H}_{n}$.

$$
\mathrm{C}_{\mathrm{m}} \mathrm{H}_{\mathrm{n} \text { ads }} \rightarrow\left(\mathrm{C}_{\mathrm{m}} \mathrm{H}_{\mathrm{n}}\right)_{\mathrm{ads}}{ }^{+}+\mathrm{e}-\quad \ldots
$$

where the subscription "ads" means the adsorbed chemical species over the surface. Positively charged adsorbates $\left(\mathrm{C}_{\mathrm{m}} \mathrm{H}_{\mathrm{n}}\right)^{+}$distill the original surface negative charge and the 
total electric conductivity of an $n$-type oxide semiconductor is increased as is illustrated in Figure $1(\mathrm{C})$. In the case of a $p$-type oxide semiconductor such as $\mathrm{NiO}$, the upward band bending is also expected due to the surface negative charge. In this case, the surface conductivity is enhanced because of the surface hole accumulation layer.

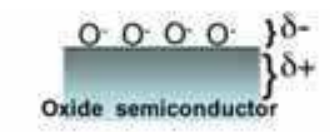

(B)
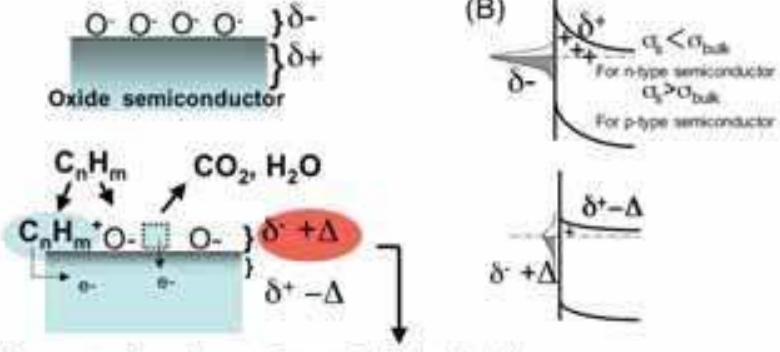

Surface negative charge is annihilated by the

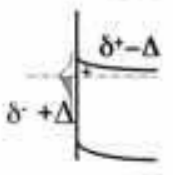

interaction with"reducing=combustible" gas molecules

(C)
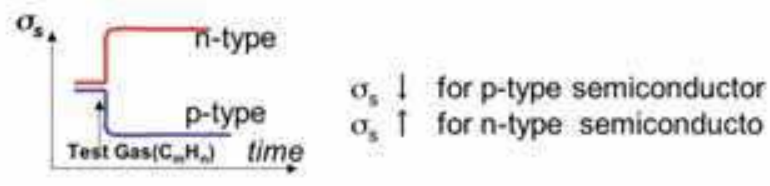

Fig. 1. Working principle of a traditional semiconductor gas sensor made by an oxide semiconductor.

Supposing Langmuir-Hinshelwood mechanisms, $\left(\mathrm{C}_{\mathrm{m}} \mathrm{H}_{\mathrm{n}}\right)^{+}$is successively oxidized to $\mathrm{CO}_{2}$ and $\mathrm{H}_{2} \mathrm{O}$ using the oxidation power of surface oxygen ions $\left(\mathrm{O}_{\mathrm{ads}}{ }^{-}\right)$.

$$
\left(\mathrm{C}_{\mathrm{m}} \mathrm{H}_{\mathrm{n}}\right)_{\mathrm{ads}}{ }^{+}+(2 \mathrm{~m}+\mathrm{n} / 2) \mathrm{O}_{\mathrm{ads}^{-}} \rightarrow \mathrm{mCO}_{2}+(\mathrm{n} / 2) \mathrm{H}_{2} \mathrm{O}+(2 \mathrm{~m}+\mathrm{n} / 2-1) \mathrm{e}^{-} \quad \ldots
$$

Totally, $(2 m+n / 2)$ electrons are donated to the semiconductor surface during the full oxidation of a $\mathrm{C}_{\mathrm{m}} \mathrm{H}_{\mathrm{n}}$ molecule. After the removal of the surface adsorbed oxygen $\left.\left(\mathrm{O}_{\mathrm{ads}}\right)^{-}\right)$, oxygen vacancies ( $\square$ in Figure 1(A)) are produced near surface but presently re-occupied by the oxygen molecules in atmosphere. When the rate of oxygen re-adsorption process,

$$
\square+1 / 2 \mathrm{O}_{2}+\mathrm{e}^{-} \rightarrow \mathrm{O}^{-} \mathrm{ads}
$$

is sufficiently slow rather than that of oxidation process (2), the surface negative charge decreases to $\delta^{-}+\Delta$, where $\delta^{-}$is the original surface negative charge by the adsorption of oxygen and $\Delta$ is the positive charge produced during the oxidation reaction, that is the summation of effective positive charge of adsorbate $\left.\left(\mathrm{C}_{\mathrm{m}} \mathrm{H}_{\mathrm{n}}\right)_{\text {ads }}{ }^{+}\right)$and oxygen vacancies induced by the reaction of $\mathrm{C}_{\mathrm{m}} \mathrm{H}_{\mathrm{n}}$. Most of the traditional semiconductor gas sensor materials are $n$-type semiconductors the response is positive, i.e., the conductivity increases by the introduction of combustible gases. As is mentioned before, if we use a $p$-type semiconductor as a gas sensor element, the effect of space charge on the surface conductivity is completely opposite and its surface conductivity is enhanced by oxygen adsorption. When $\mathrm{C}_{\mathrm{m}} \mathrm{H}_{\mathrm{n}}$ gas is introduced, the surface conductivity $\sigma_{\mathrm{s}}$ decreases by the effect of positive charge induced by partial or full oxidation of $\mathrm{C}_{\mathrm{m}} \mathrm{H}_{\mathrm{n}}$ and the response in electric conductivity is negative as is shown in Figure 1(C). 
The necessary condition for gas sensor operation by an oxide semiconductor is the procedure of the gas-surface reaction and both partial oxidation (1) and full oxidation (2) are available. If the surface of an oxide semiconductor has sufficient oxidation power against an aromatic VOC, for example benzene, it works as a benzene sensor. In the other words, oxidation power of a semiconductor surface determines whether the sensor is sensitive to benzene or not. According to the Hückel's rule, aromatic rings are thermodynamically stable and they are difficult to be fully oxidized to $\mathrm{CO}_{2}$ in a mild condition. Tin oxide $\left(n-\mathrm{SnO}_{2}\right)$ based gas sensors are usually insensitive for benzene or toluene due to its lower oxidation power for a catalyst at the operating temperature of $200-300^{\circ} \mathrm{C}$. For the detection of aromatic VOCs, severe temperature condition and the specific surface morphology having ultra-fine (sub- $\mu \mathrm{m}-\mathrm{nm}$ order) grains is required in the sensor body.

\section{The strategy for designing an aromatic VOC sensor -The "electro" activation and "photo" activation of VOC molecules for the procedure of the oxidation reaction-}

As is shown in the previous section, the most important subject for designing an aromatic VOC sensor is how to activate or ionize the target compound adsorbed over the sensor body. High temperature operation is the most easygoing way for adding the aromatic VOC sensitivity to an oxide semiconductor gas sensor. However, in this method, a high-power consumption heat source must be set in the sensor system. Therefore, this type of sensor system is not appropriate for a micro-sensor devise manufactured by the circuit integration technology.

Here, we propose two novel methods for obtaining the active sensor surface for the reaction with aromatic VOCs. One is "Electro activation" of an adsorbate of target molecules and the basic concept is summarized in Figure 2. In this process, a semiconductor pn junction interface is used as a reaction field for target gases, i.e., aromatic VOCs. The electric field at the junction interface would modify the carrier concentration of the near interface region and assist the "active" carrier injection/extraction from/to VOC molecules adsorbed over the junction region. This process is speculated by the electric theory of catalysis proposed by Wolkenstein. A semiconductor gas sensor whose principle is based on his theory had been proposed by the authors and first applied to selective $\mathrm{CO}$ gas sensing by a $p-\mathrm{CuO} / n-\mathrm{ZnO}$ heterojunction.

The other method is "photo activation" of an adsorbate by UV light incidence. This process is "direct" activation of testing gas adsorbates. It is well known that the $\pi-\pi^{*}$ transition of aromatic ring occurs by the UV-C light incidence and an electron occupied in $\pi^{*}$ orbital is so active as to be extracted by an oxidant such as holes $\left(\mathrm{h}^{+}\right)$in VB of a $p$-type oxide semiconductor. Photo-driven oxidation process for aromatic VOCs over $p$-NiO surface under UV light incidence is summarized in Figure 3. The vertical axis represents the electron potential vs. vacuum level, which is proportional to the instability of holes, i.e., the oxidation power of holes. The excited states of $\pi$ electrons of benzene ( $\pi^{*}$ state) is located $4.13 \mathrm{eV}$ with respect to the vacuum level and its electric state is near the VB edge of a $p$ - NiO. This situation enables this system to the electron transfer from the adsorbate to VB of $p$-NiO.

The important result of our study is that "electro- " and "photo-" activation never works for the VOC sensing operation by itself. The synergy effect of "electro- " and "photo-" activation is indispensable for the sensor. Detail is shown in the latter chapters. 


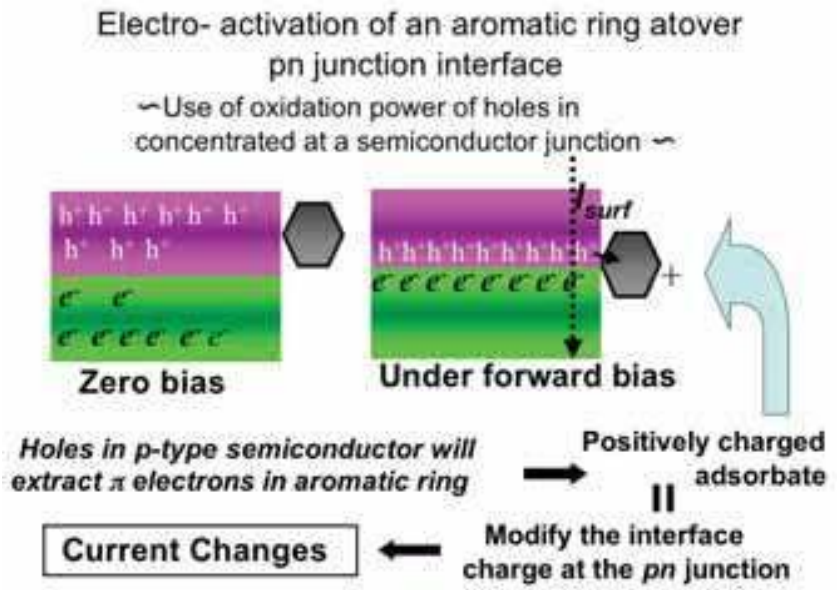

Fig. 2. The concept of "electro-" activation of combustible (reducing) gas molecules over a pn junction diode and its application to a chemical sensor.

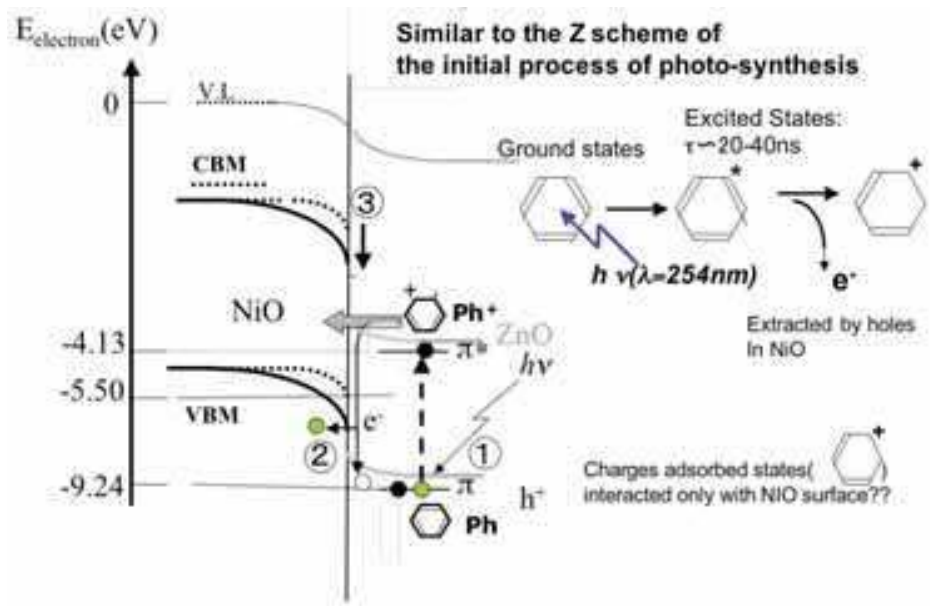

Fig. 3. Photo-driven oxidation process for aromatic VOCs over $\mathrm{p}-\mathrm{NiO}$ surface under UV light incidence. Because of the large potential gap between $\mathrm{VB}$ edge of $\mathrm{NiO}$ and ground state of aromatic VOC $(\mathbf{P h}), \mathrm{Ph}$ is not oxidized under dark, however oxidation of exited state (=electron transfer from $\mathrm{Ph}^{*}$ to $\mathrm{VB}$ of $\mathrm{NiO}$ ) is possible.

\section{4. "Electro-" activation of aromatic VOCs using a wide gap pn junction diode}

The basic concept of the electro-activation of aromatic ring: Ph by the assist of active hole injection at a pn junction interface is summarized in Figure 4(A). Applying the bias voltage causes the displacement of Fermi level at the junction interface and when the bias is applied to the forward direction, the quasi-Fermi level of holes in $p$-type semiconductor will be pulled down relative to the original level. As a result, holes in $p$-type semiconductor are concentrated 
at the junction region as is illustrated in Figure 2. Supposing the electronic theory of catalysis, total amount of charged adsorbates: $\mathrm{Ph}^{+}$and related their catalytic reaction rate varies as a function of Fermi level. Charged adsorbed species over the junction region are regarded as the surface or interface states $\left(\mathrm{Ph}^{+} / \mathrm{Ph}\right)$ and the carrier transport process through the junction will be modified as a function of their density and energy distributions. For the oxidation of thermodynamically stable molecule such as aromatic VOC, use of wide gap p-type semiconductor is appropriate, because wide gap oxide semiconductor has deep VB rather than narrow gap one. Detail is explained in the following sections.

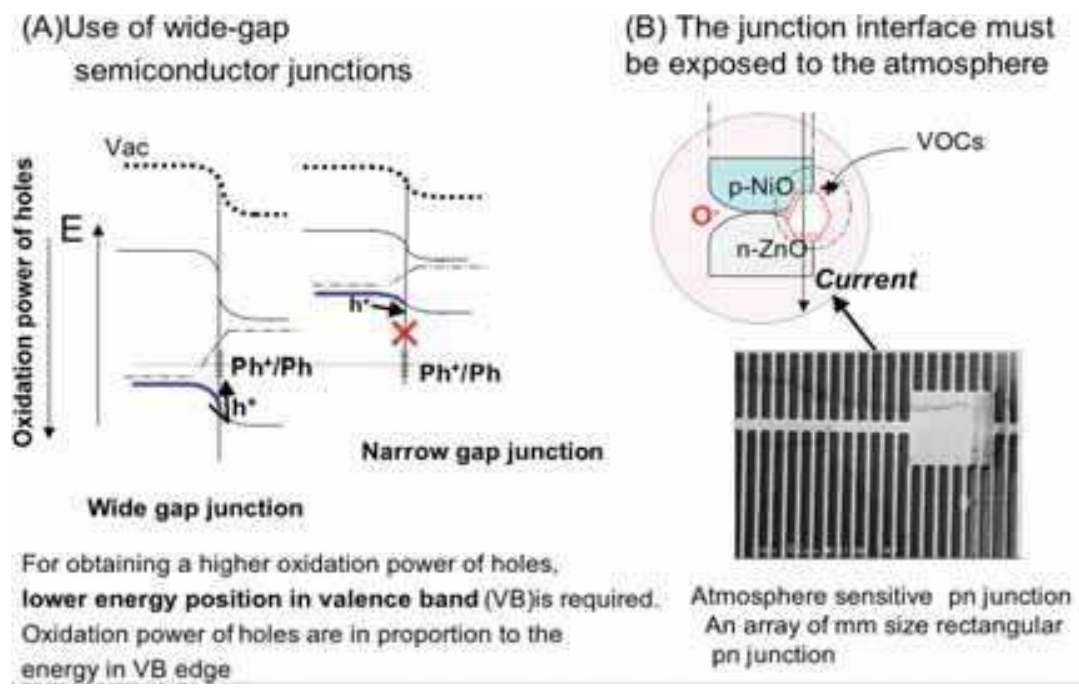

Fig. 4. How to activate an aromatic VOC $(\mathrm{Ph})$ through the "electro-"activation process at a wide gap pn junction diode. The potential gap between VB of $p$-type semiconductor and the redox potential of $\mathrm{Ph}$ becomes smaller by using a wide gap oxide semiconductors for a sensor device. For adding an atmosphere sensitive properties to a pn junction diode, the junction interface must be exposed to atmosphere by making a micro sensor array shown in Figure (B).

This phenomenon will be applied to gas sensors or other chemical sensors. Up to now, some pn heterojunctions are able to be applied for humidity monitoring, $\mathrm{CO}$ gas sensing, $\mathrm{Cl}_{2}$ gas sensing, $\mathrm{NO}_{x}$ sensing, etc. When the nano-spaces between $p$-type and $n$-type semiconductor are filled with organic solvent molecules, the electrical current passing through the contact interface dramatically changes and characteristic hysteresis loop is observed in its current-voltage (I-V) relation. By the mathematical analysis of the obtained $\mathrm{I}-\mathrm{V}$ curves, molecular recognition of the organic solvents is possible.

In the next section, we will design an atmosphere sensitive pn heterojunction diode using the continuous film preparation and patterning by photolithography as is shown in Figure 4(B).

\section{Preparation of a $p-\mathrm{NiO} / n-\mathrm{ZnO}$ heterojunction for the chemical sensor use}

In this section, we will explain how to process a pn junction diode to a chemical sensor element. According to our concept, the hetero-interface between a wide-gap $p$-type and $n$-type oxide semiconductor is appropriate for the reaction field for the oxidation of aromatic 
ring, because the contribution of "electro-" activation is expected in this field as is shown in Figure 4(A). Holes in a wide gap p-type oxide semiconductor with larger escape depth of VB electron is expected to have high oxidation power, because the stability of holes would be anti-proportional to the escape depth of VB electrons. Instability of holes indicates its higher oxidation power. The energy levels of electrons in CB of semiconductors can be closely correlated to the reduction activity of a semiconductor photo-catalyst and the similar theory can be valid for the electro-catalyst for oxidation using a $p$-type oxide semiconductor. We should select a wide gap $p$-type semiconductor with "deeper" VB.

Here, we select a wide gap $p$-type semiconductor, nickel oxide $(\mathrm{NiO})$ as a pn heterojuchtion diode for VOC sensor application and prepare a diode structure having non-epitaxial junction interface by the continuous film preparation by sputtering technique. The junction interface prepared by this method is composed of the assembly of numerous number of point junctions and there is "nano-space" around the point junctions. The carriers (electrons and/or holes) are transferred through these point junctions and their transport properties will be strongly modified in the "nano-space". If combustible gas molecules are introduced, they are transferred through "nano-space" around the point junctions. Then, combustible gases adsorb near the junction interface and their catalytic oxidation proceeds in the vicinity of the point junctions. The atmosphere sensitive pn junction diode for the use of aromatic VOC sensing is illustrated in Figure 4(B). For the efficient gas transport to pn contact junction, we design the micro sensor alley, whose dimension is several $\mu \mathrm{m}$ in length and several $\mu \mathrm{m}$ in width.

The transport properties and related gas sensing properties of an oxide semicondcutor pn junction diode depend on the crystal axis relationship between p-type and n-type semiconductor. It is appeared that the sensor properties of a pn junction based on $\mathrm{ZnO}$ strongly depend on the interface index of $\mathrm{ZnO}$. Due to the structural anisotoropy, crystal planes of $\mathrm{ZnO}$ are roughly classified to $\mathrm{Zn}$-terminated polar surface ((0001) plane, here, it is named Zn-face), O-terminated polar surface ((000-1) plane, named O-face) and non-polar surface. $\mathrm{Zn}$-face and O-face has opposite surface charge. In the $\mathrm{ZnO}$ based pn junction diode, the polarity of surface charge will strongly modify its basic junction properties.

Zinc oxide $(\mathrm{ZnO})$ substrate was prepared by vapor transport technique using $\mathrm{ZnO}$ sintered compact as a $\mathrm{ZnO}$ vapor source. Use of $\mathrm{ZnO}$ single crystal substrates for the device preparation will provide a sophisticated interface, however, such the junction device would not have gas sensing properties because the junction is too sophisticated and it prevents the introduction of "nano-space" for transferring testing gas molecules to the active sites.

Zinc oxide $(\mathrm{ZnO})$ crystals grown by the method proposed by Noritake were polycrystalline but highly oriented to the c-axis direction, whose orientation angle was limited within 0.5 degree. The photograph of an as grown crystal is shown in Figure 5 and top and bottom surface of the crystal was Zn-terminated polar surface (Zn-face) and O-terminated polar surface (O-face), respectively. Nickel oxide film was deposited on this substrate by rf magnetron sputtering technique with the thickness of $100 \mathrm{~nm}$ using a 2 at $\%$ lithium doped $\mathrm{NiO}$ sintered compact as a sputtering target. Nickel oxide $(\mathrm{NiO})$ films by this process were colored gray and its carrier concentration was evaluated to be $5 \times 10^{17} \mathrm{~cm}^{-3}$ by Hall effect measurement. The conductivity of the p-NiO film is small compared with a $\mathrm{ZnO}$ substrate, whose carrier concentration was $2 \times 10^{19} \mathrm{~cm}^{-3}$ and the potential drop at the junction region mainly occurred at the $p$ - $\mathrm{NiO}$ side. 
After the Ohmic electrode ( $\mathrm{Ni}$ and Au film) was deposited over the $\mathrm{NiO}$ film, the devise was processed into atmosphere sensitive one. Inter-digital electrode pattern was drawn by photolithography technique and chemical etching was conducted for exposing the junction interface to the atmosphere. The fabrication process of $p-\mathrm{NiO} / n-\mathrm{ZnO}$ sensor element was summarized in Figure 5. After chemical etching process in $0.1 \mathrm{M} \mathrm{HCl}$ aqueous solution, the transport properties of a $p-\mathrm{NiO} / n-\mathrm{ZnO}$ heterojunction became sensitive to the atmosphere. The top view of the inter-digital electrode was shown in Figure 4(B) and 5.

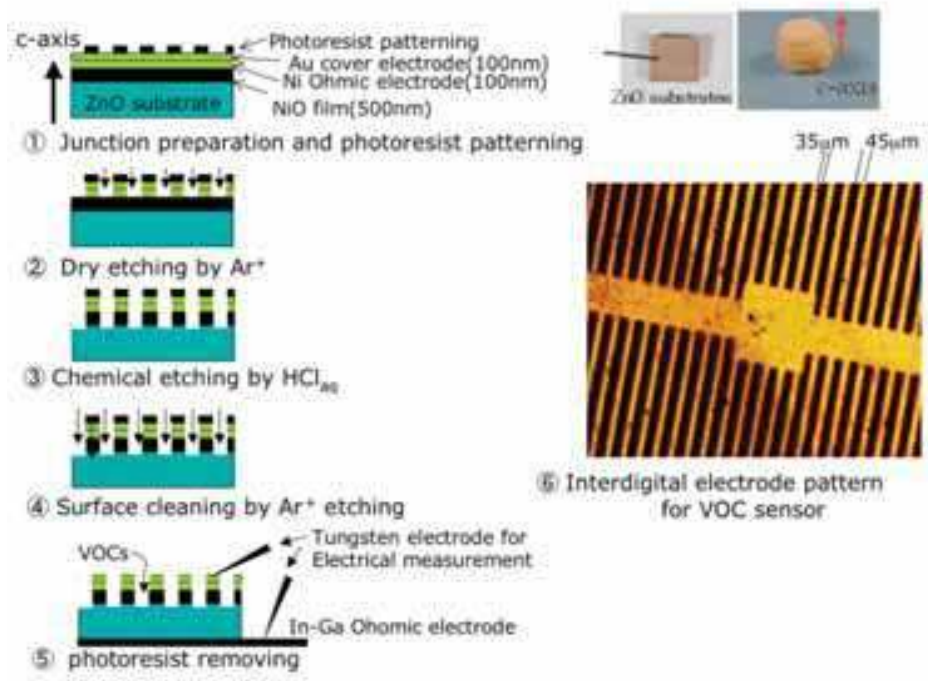

Fig. 5. Schematic view of the preparation of a $p-\mathrm{NiO} / n-\mathrm{ZnO}$ heterojunction VOC sensor element. Pn junction is prevared by depositing a $\mathrm{NiO}$ film on a highly oriented $\mathrm{ZnO}$ polycrystalline substrate. After depositing an Ohmic electrode on the junction, sensor array is prepared by photolithography patterning and chemical etching. We can prepare a $p$ - $\mathrm{NiO} / n-\mathrm{ZnO}$ heterojunction by more symple process, that is, continuous depsositing of $\mathrm{NiO}$ and $\mathrm{ZnO}$ film. Similar etching process is possible for preparing a sensor element shown in figure 6 .

\section{VOC sensing characteristics of a $\mathrm{p}-\mathrm{NiO} / \mathrm{n}-\mathrm{ZnO}$ heterojunction in the dark -Effect of "Electro-" activation of adsorbate of VOCs-}

The $I-V$ characteristics of an original, i.e., before processing to sensor array, $\mathrm{p}-\mathrm{NiO} / \mathrm{n}$ $\mathrm{ZnO}(\mathrm{Zn}$-face) heterojunction is curve 1 in Figure 6. The I-V curve looks like "good" rectifying character apparently, however, the diode factor $n$ is calculated to $n=6.2$, that means large number of interface states exist and that would contribute to the recombination current across the junction. The I-V curve is modified again by processing into a sensor element and its rectifying character is completely spoiled after the chemical etching process (Curve 2 in Figure 6). The rectifying character is restored by low temperature $\left(200^{\circ} \mathrm{C}\right)$ annealing in oxygen and simultaneously, large hysteresis is appeared in the I-V response. This characteristic I-V is the result of the extrinsic interface states, which is introduced by low temperature annealing in oxygen, therefore, carrier transport through the pn junction interface is governed by the nature of this extrinsic interface states. 

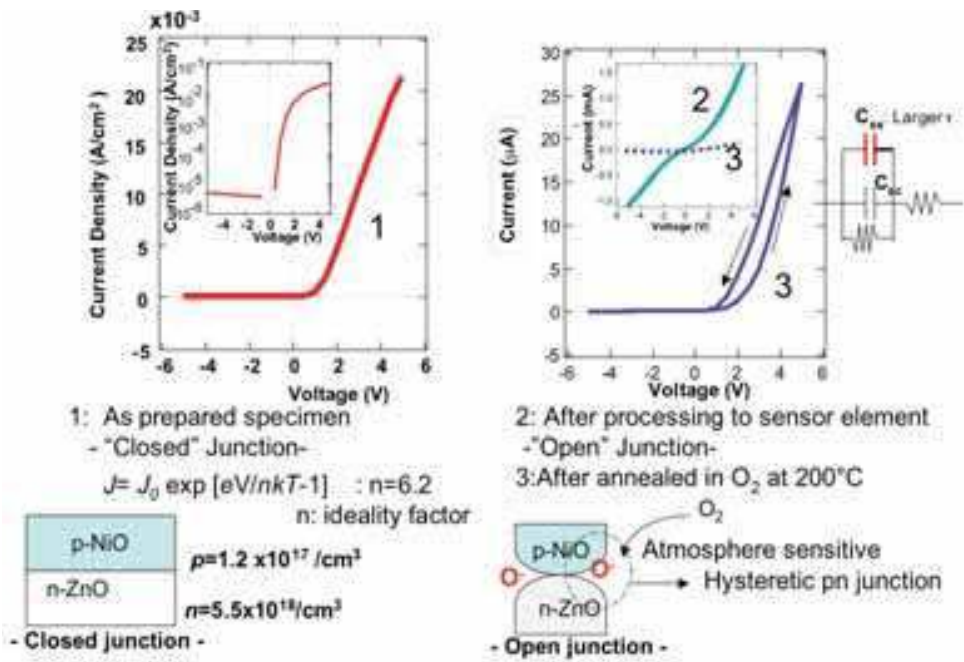

Fig. 6. The basic junction properties of a $p-\mathrm{NiO} / n-\mathrm{ZnO}(\mathrm{Zn}$-face) heterojunction prepared by continuous $\mathrm{NiO}$ and $\mathrm{ZnO}$ film deposition on a glass substrate. The rectifying character of the junction is spoiled by processing it into a micro-sensor array(curve 2). The rectifying characteristics are restored by annealing the device in oxygen atmosphere as is shown in curve 3.

Is the "electro-" activation effective for an aromatic VOC sensing at a p-NiO/n- $\mathrm{ZnO}$ heterojunction with such high density of extrinsic interface states? That is the main subject for the discussion in this section. We checked the effect of applied bias on various VOC sensing properties of a $p-\mathrm{NiO} / n-\mathrm{ZnO}$ heterojunction sensor element. In the case of the detection of simple inorganic combustible gas, such as carbon monoxide (CO), the electro-activation plays an important role for the sensor operation. In our hypothesis, positively charged $\mathrm{CO}$ adsorbate $\left(\mathrm{CO}^{+}\right)$over the $p$ - $\mathrm{CuO}$ surface promotes the carrier transport through $p$-CuO- $n$ - $\mathrm{ZnO}$ junction interface, therefore, the junction works as a $\mathrm{CO}$ gas sensor. Supposing the electronic theory of catalysis, the surface concentration of $\mathrm{CO}^{+}$adsorbates over $p$-type semiconductor changes as a function of surface Fermi level and in the case of a pn junction type gas sensor, it is enhanced by applying the forward bias. This hypothesis is well supported by our experimental results.

The question is whether such the reaction scheme is valid for the detection of a thermodynamically stable molecules such as aromatic VOCs. The $p-\mathrm{NiO} / n-\mathrm{ZnO}(\mathrm{Zn}$-face) junction resistance is not in response to aromatic VOCs, while very small response is obtained by acetone and ethanol vapor introduction(Figure 7). The current response is rather complex as is shown in Figure 7A. Just after the acetone vapor introduction, the forward current $(\mathrm{V}=+5.0 \mathrm{~V})$ rapidly increases (point $\mathrm{B}$ in Figure $7(\mathrm{~A})$ ), then, gradually decreases to current revel lower than the original value (point $\mathrm{C}$ ). Similar sensing characteristic are obtained by the introduction of ethanol vapor. A key to understanding this phenomena is "unipolar" sensing characteristics, that is a $p-\mathrm{NiO} / n-\mathrm{ZnO}(\mathrm{Zn}$-face) heterojunction sensor element works as acetone sensor only when the junction is forward biased, while it dose not work under reverse bias. As is shown in Figure $7 \mathrm{~B}$, only the forward current changes $\mathrm{A} \rightarrow \mathrm{B} \rightarrow \mathrm{C}$. The forward current shows about $7 \%$ decrease under 4300ppm of acetone (curve C in Figure 7(B)). 

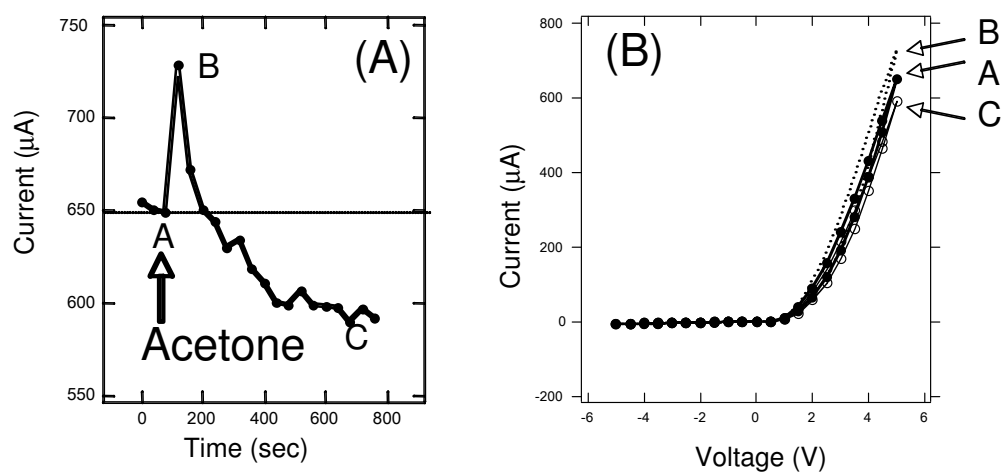

Fig. 7. The effect of acetone vapor introduction on the transport properties of a $p-\mathrm{NiO} / n-\mathrm{ZnO}(\mathrm{Zn}$-face) heterojunction sensor element under dark. The current -time behavior at $\mathrm{V}=+4.5 \mathrm{~V}$ forward bias is shown in figure (A). At the point (A), acetone vapor arrives at around the junction interface and after $600 \mathrm{sec}$ (point $\mathrm{C}$ ) the acetone concentration reaches $4300 \mathrm{ppm}$. The $\mathrm{I}-\mathrm{V}$ curve $\mathrm{B}$ is that of point $\mathrm{B}$ in figure (A).

In our acient study, we had evaluated the effect of organic solvent introduction on the I-V characteristics of a $p-\mathrm{CuO} / n-\mathrm{ZnO}$ heterojunction. When the acetone or ethanol is introduced to the junction region, forward current dramatically increases, at that time, characteristic hysteresis is grown in the reverse biased region. Initial forward current enhancement of $p-\mathrm{NiO} / n-\mathrm{ZnO}$ in Figure $7(\mathrm{~A})$ is supposed to be due to the anodic oxidation (hole injection from $p-\mathrm{NiO}$ ) of ethanol and acetone over $p-\mathrm{NiO}$ surface as is predicted in ethanol detection by a $p-\mathrm{CuO} / n-\mathrm{ZnO}$ heterojunction. As we discussed, thermodynamically stable molecules, aromatic VOCs are difficult to be detected by using $p-\mathrm{NiO} / n-\mathrm{ZnO}$ heterojunction at room temperature. These results mean that adsorbed aromatic VOC molecules are not ionized or activated by the chemical interaction with positively (or negatively) biased $p$-NiO surface at room temperature. Anodic oxidation of VOCs at a pn junction interface had thought to be profitable process for acetone or ethanol sensing, however, holes in $\mathrm{VB}$ of $\mathrm{p}-\mathrm{NiO}$ did not work an oxidant for aromatic VOCs in the ground states.

It had been known that under higher applied voltage, titanium dioxide $\left(\mathrm{TiO}_{2}\right)$ films behaves like $p$-type semiconductor because of its space charge limited current (SCLC) and turns to be sensitive for benzene at room temperature. Its working mechanism is speculated to be the creation of surface donor states due to the interaction between carriers (holes) and benzene adsorbates. In the case of the $p-\mathrm{NiO} / n-\mathrm{ZnO}$ heterojunction sensor element, though high concentration of holes are injected into the junction region at least under forward bias, electrical activation of benzene or toluene is invalid under dark. This process is valid only for orgatic compound which are easy to be oxidized.

\section{Photo-assisted aromatic $\mathrm{VOC}$ sensing of a $p-\mathrm{NiO} / \mathrm{n}$-ZnO sensor element under UV light irradiation}

As is discussed in the previous section, the oxidation power of holes in the valence band (VB) of $p$-type semiconductor is a key to designing a pn junction type VOC sensor. The oxidation power of holes is suggested to be proportional to the energy of VB edge vs. 
vacuum level. From the empirical rule, the VB position of an oxide semiconductors is at most $-7 \mathrm{eV}$ vs. vacuum level and that of $p$-type semiconductor shows $1-2 \mathrm{eV}$ higher position, therefore, even in a wide gap p-type semiconductor, holes in VB do not have sufficient oxidation power for extracting electrons from aromatic VOC adsotbates. Relative relation between the conduction/valence band of $n-\mathrm{ZnO}, p-\mathrm{NiO}$, and ground/excited states of benzene is illustrated in Figure 8. The ground state of toluene lies $-8.8 \mathrm{eV}$ below the vacuum level and that of benzene is $-9.24 \mathrm{eV}$ and those are far larger than $\mathrm{VB}$ edge of $p-\mathrm{NiO}(-5.5 \mathrm{eV})$. Benzene, toluene or other VOCs having six-membered aromatic ring is known to molecularly adsorb over a transition metal oxide (TMO) surface, whose aromatic ring is parallel to the surface as is illustrated in the upper part of Figure 8. At lower temperature, the activation energy is not sufficiently supplied due to the large potential gap $(>3 \mathrm{eV})$ between $\pi$ ground states and $\mathrm{VB}$ of $p-\mathrm{NiO}$, therefore, ionization of aromatic ring followed by the spontaneous electron transfer between adsorbate and TMO surface does not occur. Charge neutral chemical species hardly affect the carrier transport through the pn junction interface. This is the limit of the ability of "electro-activation" of adsorbates and we must consider novel concept for activating an adsorbate, that is "photo-activation".

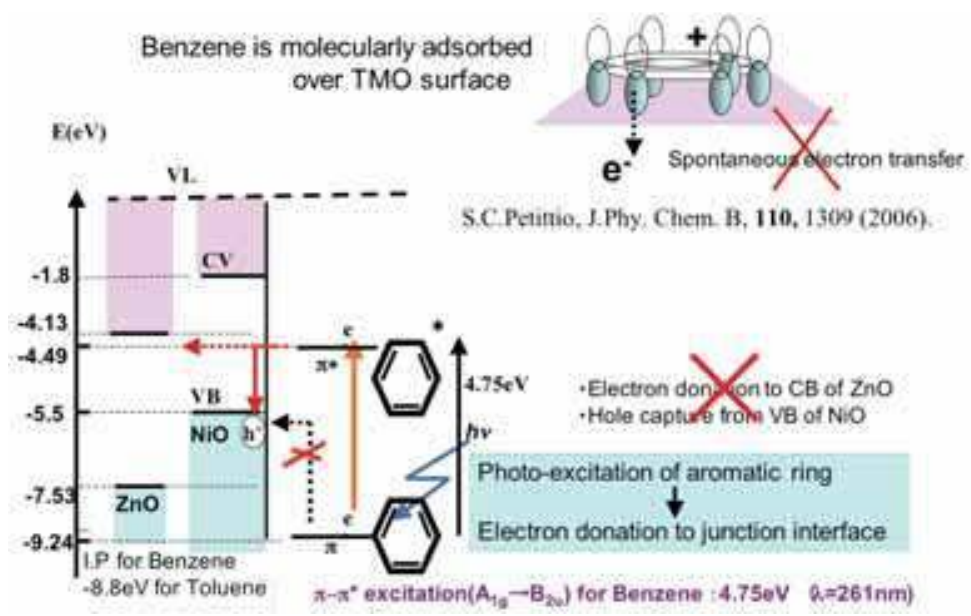

Fig. 8. Possible working principle of aromatic VOC sensing in a $p-\mathrm{NiO} / n-\mathrm{ZnO}$ heterojunction. $\pi^{*}$ electron in the excited states of benzene can interact with holes in VB of $p$ $\mathrm{NiO}$. From the experimental data, applying the forward bias is necessary for the electron transfer from $\pi^{*}$ state to the pn junction interface (red arrow in the figure). Spontaneous electron transfer dose not occur without the assist of applied bias.

Under UV light irradiation, $\pi$ electrons in aromatic ring is excited to $\pi *$ level, which is located $1 \mathrm{eV}$ above the $\mathrm{VB}$ of $p-\mathrm{NiO}$. The $\pi *$ electron is allowed to interact with holes in $\mathrm{VB}$ of $p$ - NiO and the electrons in aromatic ring is suggested to be actively transferred following the scheme in Figure 8. Such a photo-driven electron transport between semiconductor pn junction and gas adsorbate is analogous to $\mathrm{Z}$ scheme (the light reaction in photosynthesis in plants), in which one molecule of the pigment chlorophyll absorbs one photon and loses one electron having strong reduction power. In the case of the photo-driven electron transport discussed here, the process is "get one hole" having strong "oxidation" power using the photon energy. 
The analogy between the photo driven electron transport at the pn junction and Z-scheme is illustrated in Figure 9. After the electron transfer, positively ionized adsorbed species, for example, $\mathrm{C}_{6} \mathrm{H}_{6}{ }^{+}$(benzene adsorbate) will work as interface states and their positive charge will modify the interface barrier height. Therefore, the junction device works as an aromatic VOC sensor. Of course, similar scenario is expected in toluene adsorption.

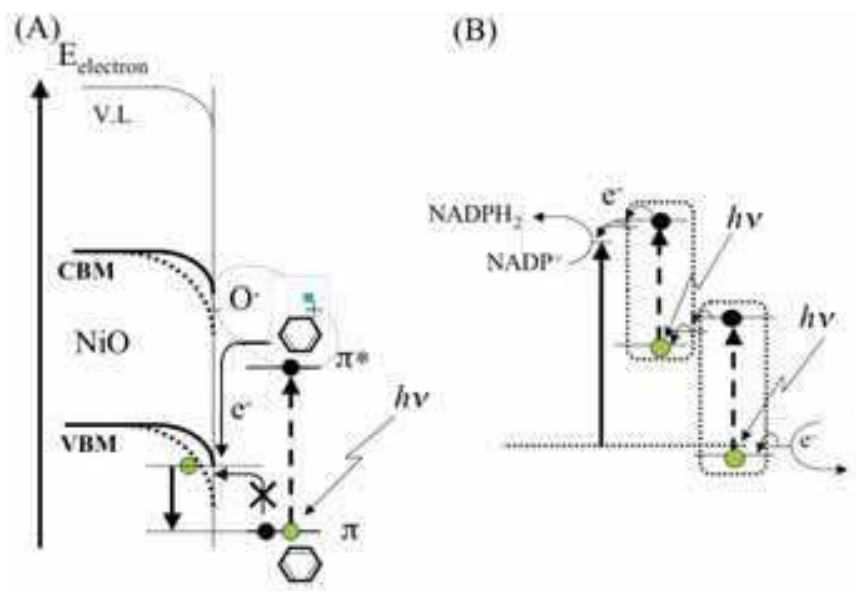

Fig. 9. The analogy between (A) VOC oxidation with the assist of photon energy and (B) light reaction (synthesis of reduction regent: $\mathrm{NADPH}_{2}$ ) in photosynthesis, which is named Z-scheme.

The effect of toluene introduction on the $\mathrm{I}-\mathrm{V}$ characteristics of a $p-\mathrm{NiO} / n-\mathrm{ZnO}(\mathrm{Zn}$-face) and $p-\mathrm{NiO} / n-\mathrm{ZnO}(\mathrm{O}$-face) heterojunction sensor elements are summarized in Figure 10 . The UV light source used in this experiment is a low pressure mercury lamp whose characteristic emission-lines are known to be $\lambda$ (wavelength) $=254,295,302,313$ and $365 \mathrm{~nm}$ in the UV region. The photon energy is sufficient for the band-to-band excitation for both $\mathrm{NiO}$ and $\mathrm{ZnO}$. Under the UV irradiation, the photocurrent flows both forward and reverse directions and the I-V curve is changed from 1(under dark) to 2 (under UV irradiation) as is shown in Figure 10.

Under UV irradiation, the toluene sensing properties are added to a $p-\mathrm{NiO} / n-\mathrm{ZnO}$ sensor element and only the forward current decreases as a function of toluene concentration in atmosphere. The I-V curve is changed from 2 to 3 after the $3325 \mathrm{ppm}$ of toluene vapor introduction. There is characteristic difference in the basic junction properties between $p-\mathrm{NiO} / n-\mathrm{ZnO}(\mathrm{Zn}$-face) and $p-\mathrm{NiO} / n-\mathrm{ZnO}(\mathrm{O}-$ face $)$ junction. The junction properties of a $p-\mathrm{NiO} / n-\mathrm{ZnO}(\mathrm{Zn}$-face) sensor element keep good rectifying character even after processing into a sensor element, while that of a $p-\mathrm{NiO} / n-\mathrm{ZnO}(\mathrm{O}$-face) sensor element shows a little leaky character and its onset potential in forward current is far smaller than that of a $p$-NiO/ $n-\mathrm{ZnO}(\mathrm{Zn}$-face) element. Though $p-\mathrm{NiO} / n-\mathrm{ZnO}$ heterojunctions show different transport and photo response properties depending on the crystal plane of the $\mathrm{ZnO}$ substrate, there is no characteristic differences in the toluene sensing properties between $p-\mathrm{NiO} / n$ $\mathrm{ZnO}(\mathrm{Zn}$-face) and $p-\mathrm{NiO} / n-\mathrm{ZnO}(\mathrm{O}$-face) sensor element. This result suggest that the nature of the $\mathrm{ZnO}$ crystal plane does not largely contribute to the toluene sensing mechanisms and the $\mathrm{ZnO}$ layer works only for the electron -injector/hole-collector at the junction region. 

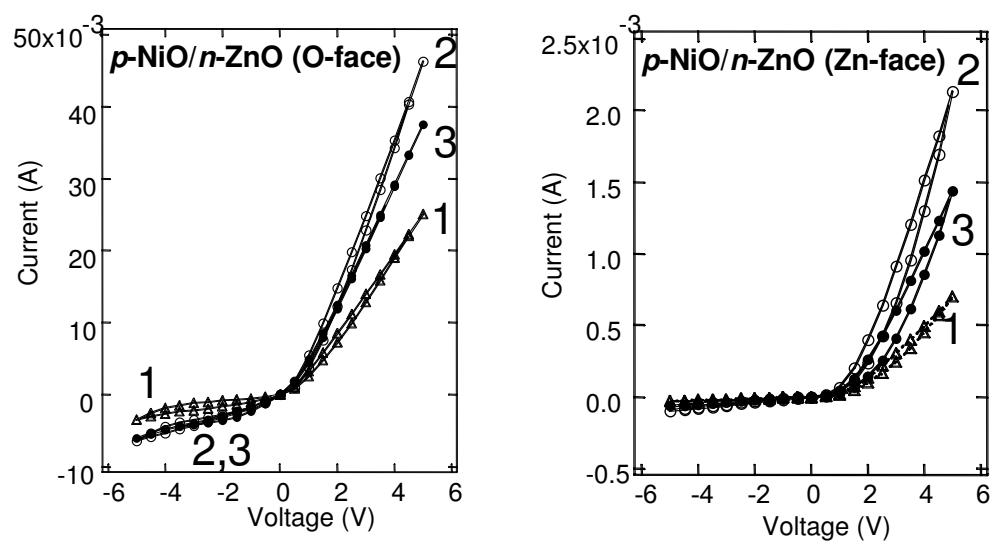

Fig. 10. The effect of toluene introduction on the I-V characteristics of a $p-\mathrm{NiO} / n-\mathrm{ZnO}(\mathrm{Zn}-$ face) and $p-\mathrm{NiO} / n-\mathrm{ZnO}(\mathrm{O}-$ face $)$ heterojunction sensor elements. Curve 1 : The I-V curve under dark, Curve 2: The I-V curve under UV light irradiation and Curve 3: The I-V curve in toluene 3325ppm atmosphere under UV light irradiation. Toluene sensing properties are added in both junctions under UV irradiation, though there are characteristic differences in the basic junction properties.
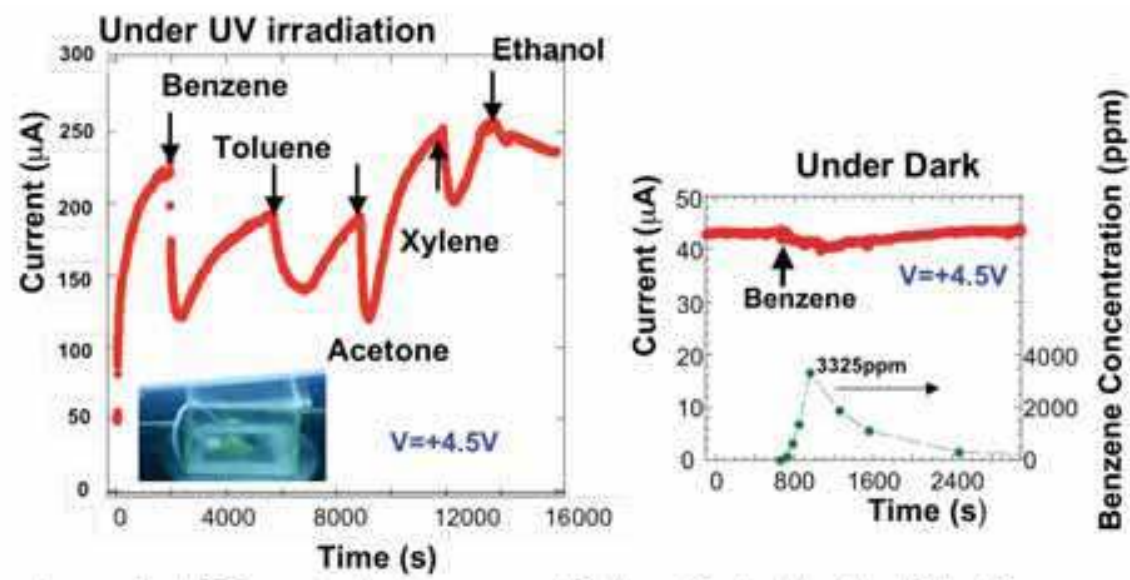

- Aromatic VOCs adsorbates are not fully activated by the "Electric activation ( Carrier injection) process at the interface.

- "Photo-activation" of adsorbates by deep UV light ( $\mathrm{Hg}$ lamp) irradiation is necessary for adding the VOC sensing properties

Fig. 11. The effect of various VOC introduction on the photo current through the $p-\mathrm{NiO} / n$ $\mathrm{ZnO}(\mathrm{Zn}$-face) junction interface under full spectra of $\mathrm{Hg}$ lamp. The $p-\mathrm{NiO} / n-\mathrm{ZnO}(\mathrm{Zn}$-face) junction is sensitive for aromatic VOCs ( Benzene, toluene, xylene... and acetone) under UV irradiation at room temperature. The sensitivity for ethanol vapor is never enhanced under UV light irradiation, while that for acetone vapor is extremely enhanced under UV irradiation. 
Independent of the crystal plane of $\mathrm{ZnO}$, the electrical current suppression by toluene introduction is clearly observed only when the $p-\mathrm{NiO} / n-\mathrm{ZnO}$ junction is biased to the forward direction. Such the unipolar gas sensing characteristics are feature of molecular sensing by a pn junction device, whose working principle is based on the "electro-" activation. Under forward bias, holes will be injected from $p-\mathrm{NiO}$ bulk into the junction interface and they will extract the $\pi *$ electrons in the excited states of toluene.

This process would not occur without the assist of carrier injection by applied bias. A $p-\mathrm{NiO}$ thin film in itself dose not show toluene sensing characteristics even under UV irradiation. Both "electro-" and "photo-"activation is indispensable for the detection of VOCs at the pn junction interface. The important subject for the design of an aromatic VOC sensor is the synergy effect of two independent activation processes, "electro-" and "photo-" activation. Similar effects are obtained by benzene, xylene and acetone introduction, because all these compounds have absorption spectra in UV region, which locate near the line spectra of mercury lamp. On the other hand, methanol and ethanol sensitivity are not enhanced under UV light irradiation. These results are summarized in Figure 11. The result under reverse bias is also shown in the right panel of this figure and you can see the reverse current did not respond to toluene introduction even under UV irradiation.

The $p-\mathrm{NiO} / n-\mathrm{ZnO}$ heterojunction shows rapid response for $\mathrm{VOC}$ in atmosphere and the current change, $\Delta \mathrm{I}\left(=\mathrm{I}_{0}-\mathrm{I}(\mathrm{t})\right.$, where $\mathrm{I}_{0}$ is the current before toluene introduction and $\mathrm{I}(\mathrm{t})$ is the current at $\mathrm{t}$ second after VOC introduction) directly related to the toluene concentration in atmosphere. The time dependence of the current change $\Delta \mathrm{I}$ (= the magnitude of the current decrease by the introduction of toluene) under forward bias is shown in Figure12. The rise and decay of the toluene concentration in the ambient after the toluene injection is overplotted. The current decreased rapidly following the toluene concentration and $\Delta \mathrm{I}$ was appeared to be proportional to the square root of the toluene concentration, whereas no remarkable current modulation was observed under reverse bias. Rapid response is the great advantage for the use of environmental monitoring.

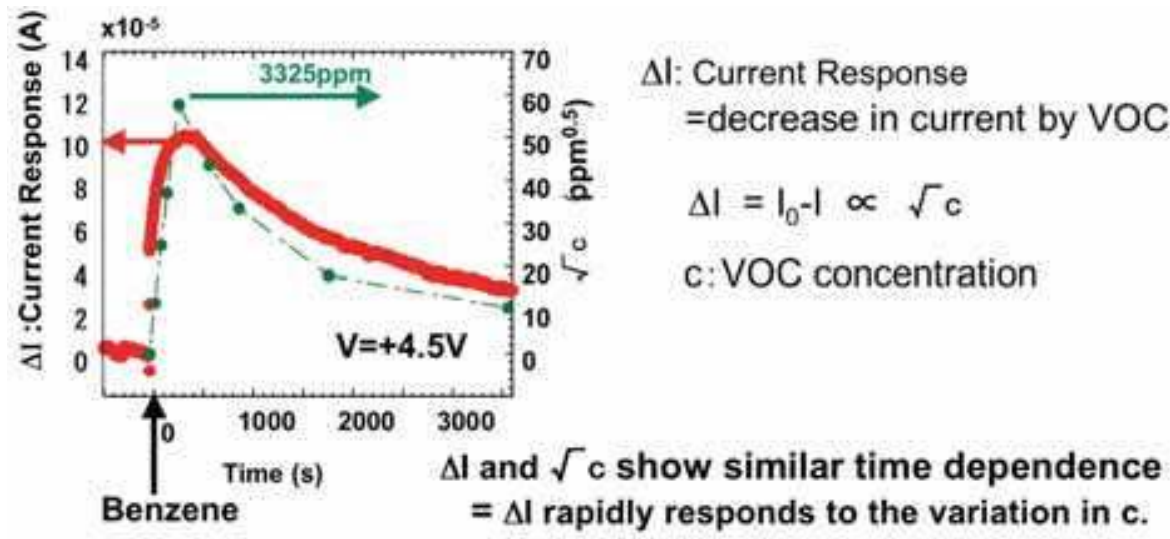

Fig. 12. The time dependence of the current decease by toluene introduction $(\Delta \mathrm{I})$ and toluene concentration in atmosphere, c. $\Delta \mathrm{I}$ is proportional to the square root of $\mathrm{c}(\sqrt{ } \mathrm{c})$. 
Here, we discuss the working mechanisms of toluene sensing by a $p$ - $\mathrm{NiO} / n-\mathrm{ZnO}$ heterojunction under UV irradiation in detail. The next experiment gives us important information on the VOC sensing mechanism. That is, a simple photo-catalytic reaction will be invalid for promotion of toluene or benzene sensing characteristics in a $p-\mathrm{NiO} / n-\mathrm{ZnO}$ sensor element. Figure 13 shows the effect of the spectrum of UV light source on the toluene sensing characteristics of $p-\mathrm{NiO} / n-\mathrm{ZnO}(\mathrm{Zn}$-face) sensor element. When the UV light source with full spectrum is switched on, band-to-band excitation of $\mathrm{NiO}$ and $\mathrm{ZnO}$ occurs and the photocurrent flows through the junction. The measurement in Figure 13 is conducted under forward bias $(\mathrm{V}=+4.5 \mathrm{~V})$ and in this condition, the current rapidly decreases by the introduction of aromatic VOC (benzene) vapor in atmosphere. However its sensing characteristics are completely spoiled by cutting off $\lambda=254 \mathrm{~nm}$ UV light using PYREX glass filter. Even if $\lambda=254 \mathrm{~nm}$ UV light is missing, the photocurrent still flows because the band to band excitation of $\mathrm{NiO}$ and $\mathrm{ZnO}$ is still possible by the adsorption of $\lambda=295,302,313$ and $365 \mathrm{~nm}$ line of the UV source.

It had been reported that La doped $\mathrm{ZnO}$ film having $\mathrm{nm}$ sized grains shows toluene sensing characteristics under UV $(\lambda=356 \mathrm{~nm})$ irradiation by UV-LED. Photo-catalytic reaction will promote its gas sensing characteristics, however, the effect is limited at elevated temperature $\left(>150^{\circ} \mathrm{C}\right)$. Taking a look at the result in Figure 13, photo-generated carriers at the $\mathrm{NiO} / \mathrm{ZnO}$ interface dose not directly promote the activation and reaction of aromatic VOCs. That is, $\lambda=254 \mathrm{~nm}$ deep UV light incidence is essential for aromatic VOC sensing operation and it might cause the direct activation of aromatic ring of toluene or benzene. In wet atmosphere, the photo-catalytic activity of $\mathrm{TiO}_{2}$ are known to be promoted by deep UV light incidence, however, in that case, UV light $(\lambda=254 \mathrm{~nm})$ is used for the production of $\mathrm{OH}$ radicals, and that would not valid in our cases, because all our measurement is conducted in dry conditions.
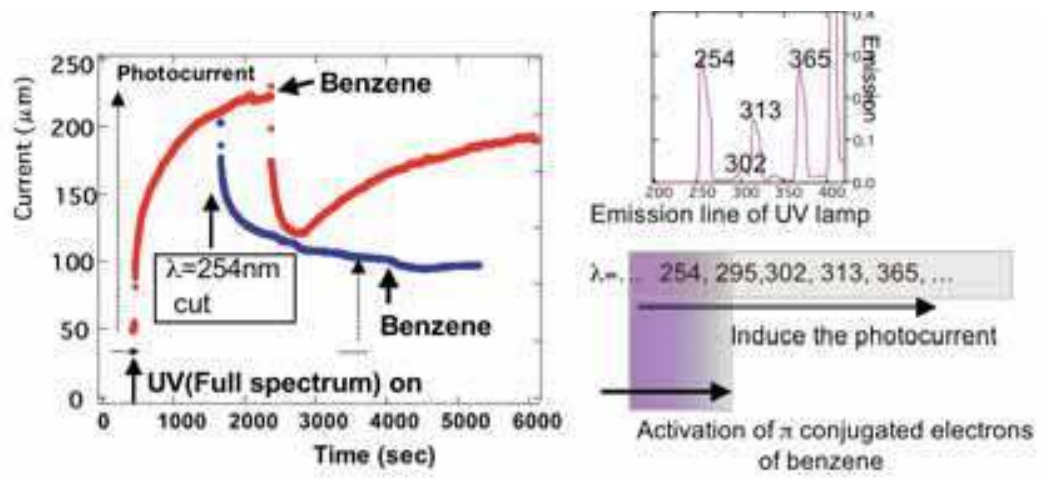

- Photo current (=carrier injection)do not assist the VOC sensing independently.

- $\lambda=254 \mathrm{~nm}$ deep UV light

- incidence is indispensable for benzene sensing of a $\mathrm{p}-\mathrm{NiO} / \mathrm{n}-\mathrm{ZnO}$ heterojunction

Fig. 13. Effect of $\lambda=254 \mathrm{~nm}$ irradiation of mercury UV lamp on the aromatic VOC (benzene) sensing characteristics of $p-\mathrm{NiO} / n-\mathrm{ZnO}(\mathrm{Zn}$-face) heterojunction sensor element. The sensitivity for benzene is disappeared when the $\lambda=254 \mathrm{~nm}$ emission line is cut off. 
The first excited state of $\pi$ conjugated electron, $\pi *$ state $\left({ }^{1} \mathrm{~B}_{2 \mathrm{u}}\right)$ of aromatic ring for toluene is $4.69 \mathrm{eV}$ higher than $\pi$ ground state $\left({ }^{1} \mathrm{~A}_{1 \mathrm{~g}}\right)$, corresponding to the photon energy of $\lambda=266.8 \mathrm{~nm}$. The $254 \mathrm{~nm}$ line of mercury lamp can excite the ground state, $\pi$ electrons to $\pi^{*}$ state, as a result, aromatic ring will become unstable and activated. The $\pi^{*}\left({ }^{1} \mathrm{~B}_{2 \mathrm{u}}\right)$ state of aromatic ring is located $4.13 \mathrm{eV}$ with respect to vacuum level (V.L.) for toluene and $4.34-4.53 \mathrm{eV}$ for benzene. The lifetime of the excited state of toluene is evaluated to be $26 \sim 45 \mathrm{~ns}$ and these are possible values for the electron transfer from $\pi^{*}$ excited state to the surface of $\mathrm{NiO}$ (or $\mathrm{ZnO}$ ), if the orbital overlap between the adsorbate and $\mathrm{NiO}$ ( or $\mathrm{ZnO}$ ) surface is sufficiently large. Judging from the energy of $\mathrm{CB}$ edge of $\mathrm{ZnO}$, electron donation from $\pi^{*}$ of toluene to $\mathrm{CB}$ of $\mathrm{ZnO}$ would be theoretically possible, however it is against the experimental results, because the positively ionized adsorbate would decrease the surface barrier height of $n$ - $\mathrm{ZnO}$.

Our speculation is supported by the following experimental result. Figure 14 shows the absorption spectra of toluene, benzene, acetone and ethanol. The line spectra of UV light source are over-plotted in this figure. From the result of Figure 11, the current rapidly decreases by toluene, benzene or acetone introduction, while no enhanced sensitivity for ethanol is observed under UV irradiation. VOCs which are detectable by a $p-\mathrm{NiO} / n-\mathrm{ZnO}$ sensor element have absorption line located around $\lambda=254 \mathrm{~nm}$ emission line, while ethanol have no absorption lines coincidence with $\mathrm{Hg}$ emission spectrum.
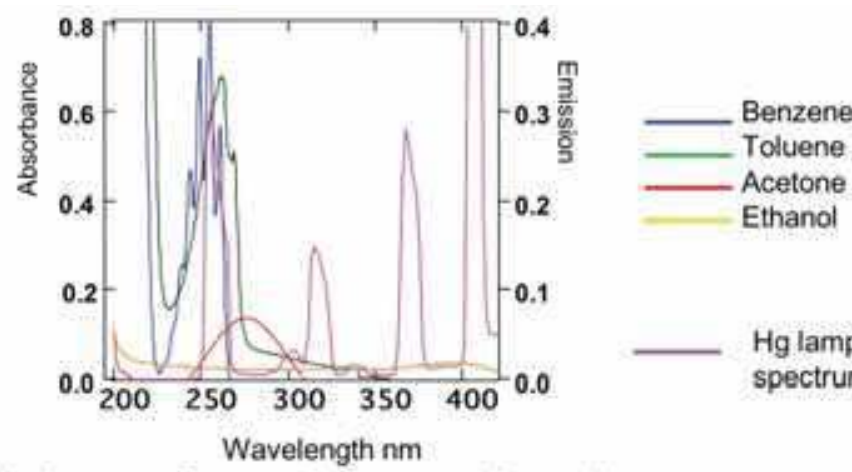

Hg lamp emission spectrum

- $\pi \rightarrow \pi^{*}$ excited states of aromatic ring were induced by $\lambda=254 \mathrm{~nm}$ UV light incidence

\section{Benzene, Toluene, Acetone $\rightarrow$ Detectable by p-NiO/n-ZnO heterrojunction Ethanol $\rightarrow$ Extremely low sensitivity}

\section{VOCs having an absorption around $\lambda=254 \mathrm{~nm}$ line can be detectable using a p-NiO/n-ZnO heterojunction under UV irradiation}

Fig. 14. The absorption spectra of toluene, benzene, acetone and ethanol in the UV region. The line spectrum of UV light source is over-plotted in this figure. Ethanol has no absorption in this energy region and the enhanced ethanol sensitivity of $p$ - $\mathrm{NiO} / n-\mathrm{ZnO}$ sensor element is not observed even under UV irradiation (shown in Figure 11). 
The toluene sensing mechanism is speculated as follows. Under $\lambda=254 \mathrm{~nm} \mathrm{UV}$ light irradiation, adsorbed toluene at the pn junction interface is activated and $\pi$ conjugated electrons are excited to $\pi^{*}$. Due to the long lifetime, $\pi^{*}$ electrons of aromatic ring can react with holes artificially injected and concentrated in $p$-NiO layers by the forward bias applied to the pn junction interface. Active hole injection by applied bias is indispensable for the sensor operation and this speculation is supported by the fact that $\mathrm{NiO}$ film itself shows no response for toluene vapor even under full spectrum of UV irradiation. Positive extracharge introduced by positively ionized toluene adsorbates would decrease or neutralize the interface negative excess charge by adsorbed oxygen or something, then the barrier height of the near-interface of $p$-NiO increases and the current passing through the junction interface decreases as a function of the aromatic VOC concentration.

These processes will be the primary step in full oxidation of aromatic ring over the $p-\mathrm{NiO} / n$ $\mathrm{ZnO}$ junction interface. When one electron is extracted from aromatic ring, extra stability of aromatic compound, which is explained by Hückel's rule is diminished and then successive oxidation reaction would proceed accompanied by the consumption of the adsorbed oxygen over the $\mathrm{NiO} / \mathrm{ZnO}$ interface. However, further discussion will be needed for determining whether the UV assisted full oxidation of aromatic VOCs proceeds over forward biased $p$ $\mathrm{NiO}-n-\mathrm{ZnO}$ junction interface.

\section{Conclusions and perspective}

The authors succeeded to detect aromatic VOCs by using $p-\mathrm{NiO} / n-\mathrm{ZnO}$ heterojunction sensor element under UV irradiation. The operation temperature is very low and it works even at room temperature. The core mechanism for aromatic VOC detection by a wide gap pn junction is the synergy effect of "electro-" and "photo-" activation of VOC adsorbates, that is, and active carrier injection followed by the photo-driven oxidation (positive ionization) of aromatic ring, which is triggered by remarkable UV irradiation of $\lambda=254 \mathrm{~nm}$ by a mercury lamp.

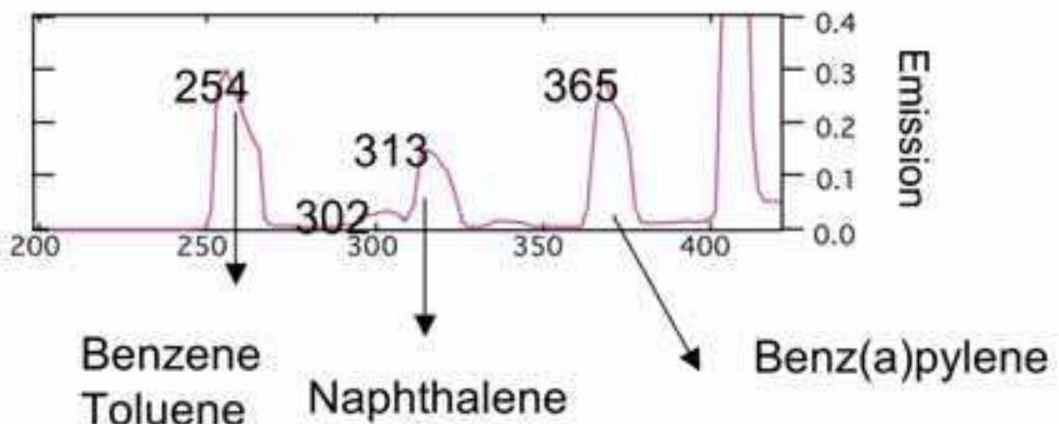

Fig. 15. The relation between the emission spectrum of mercury lamp and the $\pi-\pi^{*}$ absorption line of various aromatic VOCs. 
Another novel function, molecular recognition will be expected and molecular recognition of $\pi$ conjugated electrons systems would be possible by tuning the wavelength of excitation light source. The $\pi-\pi^{*}$ absorption line of various aromatic VOCs are over-plotted in Figure 15. For example, molecular recognition of benz(a)pylene, a deadly poisonous molecule, would be possible by tuning the wavelength of excitation light to $\lambda=365 \mathrm{~nm}$.

\section{References}

C.A. Redlich, J.Sparer, M.R. Cullen, (1997), Sick-building syndrome, The Lancet, Vol.349, Issue.9057, pp.1013-16, ISSN 0140-6736

U. Schlinka, M. Rehwagena, M. Dammb, M. Richtera, M. Bortec, and O.Herbarth, (2004), Seasonal cycle of indoor-VOCs: comparison of apartments and cities, Atmospheric Environment, Vol. 38, pp.1181-90, ISSN 1352-2310

N.Yamazoe, G.Sakai, and K.Shimanoe, (2003), Oxide semiconductor gas sensors, Catalysis Surveys from Asia, Vol.7 Issue 1, pp.63-75, ISSN 1571-1013.

C.J.Martinez, B.Hockey, C. B. Montgomery, and S. Semancik, (2005), Porous Tin Oxide Nanostructured Microspheres for Sensor Applications, Langmuir, Vol.21, Issue 17, pp.7937-44, ISSN 0743-7463

H.Yanagida, (1988), Intelligent Materials-A New Frontier, Ang. Chem., Vol.100, Issue 10, pp.1143-46, ISSN 0044-8249

H.Ohta, M.Hirano, K.Nakahara, H.Maruta, T.Tanabe, M.Kamiya, T.Kamiya, and H.Hosono, (2003), Fabrication and photoresponse of a pn-heterojunction diode composed of transparent oxide semiconductors, $p-\mathrm{NiO}$ and $n-\mathrm{ZnO}, A p p l$. Phys. Lett., Vol.83, Issue 5, pp.1029-31 (2003).ISSN 0003-6951

H.Ohta, M.Orita, M.Hirano and H.Hosono, (2000), Current injection emission from a transparent $\mathrm{p}$-n junction composed of p-SrCu2O2 Õn-ZnO,Appl.Phys.Lett. Vol.77, Issue4, pp.425-27, ISSN 0003-6951

W. H. Weinberg,(1991), Kinetics of Surface Reactions, in Dynamics of Gas- Surface Interactions, edited by C. T. Rettner and M. N. R. Ashfold, Royal Society of Chemistry, London, pp. 171, ISBN 0-85186-853-3.

S.Kikuchi, (1997),A History of the Structural Theory of Benzene - The Aromatic Sextet Rule and Huckel's Rule, el Chem. Education, Vol.74, pp.194-201 ISSN 0021-9584

T.H.Wolkenstein, (1960), "Electronic Theory of Catalysis", Advances in Catalysis, Vol.12, pp.189, Academic Press, NY, ISBN 0-12007-813-9

Y.Nakamura, H.Yoshioka, M.Miyayama, H.Yanagida, T.Tsturutani, O.Okada, and Y.Nakamura, (1990), Selective CO Gas Sensing Mechanism with $\mathrm{CuO} / \mathrm{ZnO}$ Heterocontact, elElectrochem.Soc., Vol.137,Issue 3, pp.940-43, ISSN 0013-4651

T.Hashimoto, H.Nakano, and K.Hirao, (1996), Theoretical study of the valence $\Pi \rightarrow \Pi \square$ excited states of polyacenes: Benzene and naphthalene, IChem.Phys., Vol,104, Issue 16, 6244-58, ISSN 0021-9606

Y.Ishida, A.Fujimori, H.Ohta, M.Hirano and H.Hosono,(2006), Potential profiling of the nanometer-scale charge-depletion layer in $n-\mathrm{ZnO} / p-\mathrm{NiO}$ junction using photoemission spectroscopy, Appl. Phys.Lett., 89, paper No.153502, ISSN 0003-6951 
Y.Nakamura, Y.Ariga, A.Kishimoto, M.Miyayama, O.Okada, and H.Yanagida, (1999), Electric Control of the Chemical Reaction in Ceramic-Ceramic Interface-Modeling of the Reaction Scheme, el Electroceramics, Vol.4, Issue S-1, pp.105-112, ISSN 13853449

R.A.Marra, Y.Nakamura, S.Fujitsu and H.Yanagida,(1986), Humidity Sensitive Electrical

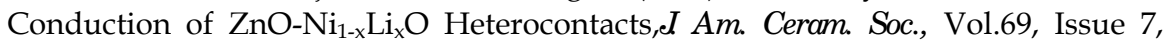
pp.C-143 -47, ISSN 0002-7820

Y.Nakamura, A.Ando, T.Tsurutani, O. Okada, M.Miyayama, K.Koumoto and H. Yanagida,(1986), Gas Sensitivity of CuO/ZnO Heterocontact, Chem. Lett., Vol.15, Issue 3, pp.413-416, ISSN 0366-7022

M.Miyayama, H.Yatabe, Y.Nakamura and H.Yanagida, (1987), Chlorine Gas Sensing Using $\mathrm{ZnO/SiC} \mathrm{Hetero-contact,} \mathrm{el} \mathrm{Ceram} \mathrm{Soc.,} \mathrm{epn,Vol.95,} \mathrm{Issue} \mathrm{11,} \mathrm{pp.1145-47,} \mathrm{ISSN} \mathrm{0914-}$ 5400 .

Y.Nakamura, S.Ishikawa, R.Koyama, and H.Yanagida, (1994), $\mathrm{NO}_{\mathrm{x}}$ Sensing Characteristics of $\mathrm{SiC} / \mathrm{ZnO}$ Heterocontact, el Ceram. Soc., epn, International Edition, Vol.102, pp.27278, ISSN 0914-5400.

K.Hirota, M.Miyayama, Y.Nakamura and H.Yanagida, (1994), Quantitative Analysis of Ethanol in Water Solution by a Heterocontact-type Sensor of $\mathrm{CuO} / \mathrm{ZnO}$, Chem. Lett., Vol.23, Issue 10, pp.1793-96, ISSN 0366-7022

Y.Nakamura, M.Ikejiri, M.Miyayama,K.Koumoto, and H.Yanagida, (1985), The CurrentVoltage Characteristics of a $\mathrm{CuO} / \mathrm{ZnO}$ Heterojunction, Nippon Kagakukai-shi, Vol.1985, Issue 6, pp.1154-59, ISSN 0369-4577

H.Hosono and T.Kamiya,(2003), Research on Ceramic Materials based on the Analysis of Electronic States, Ceramics, cpn., Vol.38, Issue 10, pp.825-31, ISSN 0009-031X

M.Fujii, T.Kawai and S.Kawai,(1984), Photocatalytic activity and the energy levels of electrons in a semiconductor particle under irradiation, Chem. Phys. Lett., Vol.106, Issue 6, pp.517-22, ISSN 0009-2614

Y.Nakamura, H.Aoki, A.Kishimoto, and H. Yanagida, (2000), The Effect of Ambient Gases on the Carrier Transport through the $\mathrm{YBa}_{2} \mathrm{Cu}_{3} \mathrm{O}_{7-\mathrm{d}} / \mathrm{ZnO}$ Heterocontact Interface, Mass and Charge Transport in Inorganic Materials, Part B, Edited by P.Vincenzini and V.Buscaglia, pp.1463-70, Techna Srl., Faenza, ISBN 88-86538-39-1

Y.Nakamura, Y.Yoshida, Y.Honaga and S.Fujitsu, (2005), Design of a Gas Sensitive Transparent Heterojunction -the system $\mathrm{SrCu}_{2} \mathrm{O}_{2}-\mathrm{ZnO}-$, el Euro. Ceram. Soc., Vol.25, Issue 12, pp.2167-70, ISSN 0955-2219

F. Noritake, N. Yamamoto, Y. Horiguchi, S. Fujitsu, K. Koumoto and H.Yanagida, (1991), Vapor-Phase Growth of Transparent Zinc Oxide Ceramics with c-axis Orientation, I Am. Ceram. Soc. Vol.74 Issue 1, 232-33 ISSN 0002-7820

Y.Hou, X.Wang, L.Wu, Z.Ding, and X.Fu, (2006), Efficient Decomposition of Benzne Over a b- $\mathrm{Ga}_{2} \mathrm{O}_{3}$ Photocatalyst under Ambient Conditions, Environ. Sci. Tech., Vol.40, Issue 18, pp.5799-5803, ISSN 0013-936X

M.J.Dewitt, D.W.Peters, and R.J.Levis, (1997), Photoionization/dissociation of alkyl substituted benzene molecules using intense near-infrared radiation Chem. Phys., Vol.218,Issue 1-2, pp.211-23, ISSN 0301-0104 
S.C.Petittio, E.M. Marsh, and M.A. Langell, (2006), Adsorption of Bromobenzene on Periodically Stepped and Nonstepped NiO(100), cI Phy. Chem. B, Vol.110, Issue 3, pp.1309-18, ISSN 6106/1089-5647 


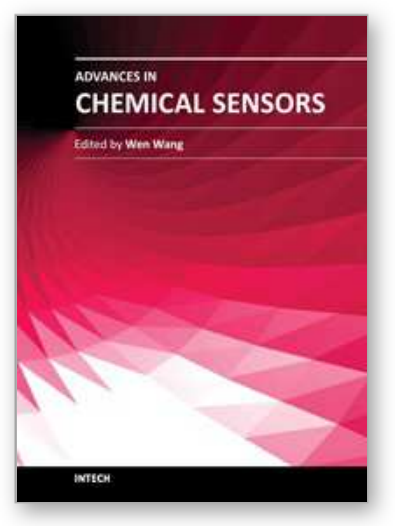

\author{
Advances in Chemical Sensors \\ Edited by Prof. Wen Wang
}

ISBN 978-953-307-792-5

Hard cover, 358 pages

Publisher InTech

Published online 20, January, 2012

Published in print edition January, 2012

The chemical sensor plays an essential role in the fields of environmental conservation and monitoring, disaster and disease prevention, and industrial analysis. A typical chemical sensor is a device that transforms chemical information in a selective and reversible way, ranging from the concentration of a specific sample component to total composition analysis, into an analytically useful signal. Much research work has been performed to achieve a chemical sensor with such excellent qualities as quick response, low cost, small size, superior sensitivity, good reversibility and selectivity, and excellent detection limit. This book introduces the latest advances on chemical sensors. It consists of 15 chapters composed by the researchers active in the field of chemical sensors, and is divided into 5 sections according to the classification following the principles of signal transducer. This collection of up-to-date information and the latest research progress on chemical sensor will provide valuable references and learning materials for all those working in the field of chemical sensors.

\title{
How to reference
}

In order to correctly reference this scholarly work, feel free to copy and paste the following:

Yoshinobu Nakamura, Yusuke Morita, Yui Ishikura, Hidenori Takagi and Satoru Fujitsu (2012). Photo-Assisted Organic Pollutants Sensing by a Wide Gap pn Heterojunction, Advances in Chemical Sensors, Prof. Wen Wang (Ed.), ISBN: 978-953-307-792-5, InTech, Available from: http://www.intechopen.com/books/advancesin-chemical-sensors/photo-assisted-organic-pollutants-sensing-by-a-wide-gap-pn-heterojunction

\section{INTECH}

open science | open minds

\section{InTech Europe}

University Campus STeP Ri

Slavka Krautzeka 83/A

51000 Rijeka, Croatia

Phone: +385 (51) 770447

Fax: +385 (51) 686166

www.intechopen.com

\section{InTech China}

Unit 405, Office Block, Hotel Equatorial Shanghai

No.65, Yan An Road (West), Shanghai, 200040, China

中国上海市延安西路65号上海国际贵都大饭店办公楼 405 单元

Phone: +86-21-62489820

Fax: $+86-21-62489821$ 
(C) 2012 The Author(s). Licensee IntechOpen. This is an open access article distributed under the terms of the Creative Commons Attribution 3.0 License, which permits unrestricted use, distribution, and reproduction in any medium, provided the original work is properly cited. 